\title{
Control of pecking response form in the pigeon: Topography of ingestive behaviors and conditioned keypecks with food and water reinforcers
}

\author{
BRENT LAMON and H. PHILIP ZEIGLER \\ Hunter College, City University of New York, New York, New York \\ and American Museum of Natural History, New York, New York
}

\begin{abstract}
In Experiment 1, the form of keypecks produced in an autoshaping procedure with food or water reinforcers was compared with that of eating and drinking responses. Because the responses involve a number of different effector systems, several elements of response form were measured, including peck force and duration, gape, and eye closure. Gape was the only measure to reliably distinguish between both ingestive responses and between conditioned keypecks reinforced with food or water. With either reinforcer, keypecks had greater force than did ingestive behaviors. In Experiment 2, a transition between two forms of keypeck was produced by manipulating deprivation and reinforcer conditions. Some measures appeared to vary in a dichotomous manner between two discrete response forms; gape showed a gradual and continuous change involving the production of intermediate forms of the response. It was concluded that the control of conditioned response form involves the construction of the response from movements produced by several effector systems, each with potentially different sources of control.
\end{abstract}

The control of response form and its relation to motivational variables constitutes a central problem in the study of behavior. An account of the factors that produce a particular behavior must ultimately consider the organization and patterning of the specific movements involved. Hungry animals eat, thirsty animals drink, animals groom their bodies, and in many species these behaviors involve the same effector systems (e.g., the orofacial musculature). Nevertheless, the topographies of eating, drinking, and grooming are as distinct and identifiable as are their functional consequences.

In the pigeon, for example, eating and drinking are both mediated by the same effector systems (neck and jaw muscles), but their topographies are quite distinct. Eating involves brief, episodic pecking responses with gape sizes, adjusted prior to contact, that vary directly with the size of the food object (Deich, Klein, \& Zeigler, 1985; LaMon \& Zeigler, 1984; Zeigler, Levitt, \& Levine, 1980). Drinking responses are of considerably longer duration, and involve a sustained and rhythmic opening and closing of the mouth with a relatively small and invariant maximum gape (Klein, LaMon, \& Zeigler, 1983). Dur-

Supported by Research Grants BNS 85-07374, from the National Science Foundation, and MH-37219 and MH-08366, from the National Institute of Mental Health, by Research Scientist Award MH-00320, and by the Biopsychology Program, Hunter College (CUNY). We wish to acknowledge the assistance of Madeleine LaMon, John VanLaer, and R. W. Allan. The present address of the first author is P.O. Box 16, St. Mary's College, Moraga, CA 94575 . Reprints may be requested from H. P. Zeigler, West Laboratory, American Museum of Natural History, New York City, NY 10024. ing these ingestive behaviors, the source of the differences in topography is obscure because several causal factors that may control topography are simultaneously present. These include deprivation condition, visual stimuli from the food or water, and orosensory stimuli produced during ingestion. Normally, all three of these variables are congruent with respect to either food or water; for example, the bird emitting eating responses is food-deprived and exposed to both visual and orosensory stimuli from the food. It is thus difficult to disentangle the relative contribution of the several causal variables to the control of response form. The experimental analysis of response form requires a behavioral preparation in which response topography may be quantified while its putative controlling variables are independently manipulated.

Several considerations suggest that the pigeon's pecking behavior may provide such a preparation. First is the fact that the same effector systems (neck and jaw muscles) mediate both the ingestive and conditioned pecking behavior of the pigeon. Second is the repeated observation that there are striking similarities between the form of ingestive behaviors and that of conditioned pecking responses (e.g., Jenkins \& Moore, 1973; Wolin, 1968; Woodruff \& Williams, 1976). These similarities suggest that conditioning paradigms may provide useful procedures for bringing response topography under experimental control. However, despite the obvious importance of these similarities for conditioning theory (Hilgard, 1936; Jenkins \& Moore, 1973; Schwartz \& Gamzu, 1977; Woodruff \& Williams, 1976; Zener, 1937), there have been few systematic and quantitative comparisons of the 
topography of the two response classes. Because of the potential significance of such comparisons, we have reexamined the relationship between ingestive and conditioned pecking and explored some of the factors that control the form of the conditioned pecking response.

In the first experiment, we measured several features of the pigeon's eating and drinking response topography, including force and duration of substrate contact, gape, and amount of eye opening. We then compared the topographies of these ingestive behaviors with conditioned keypecks made by the same subjects reinforced with food or water. In Experiment 2, we produced a controlled transition between two topographically distinct forms of the conditioned keypeck, one reinforced with food and the other with water, in order to examine the manner in which changes in topography were produced during the period of transition.

\section{EXPERIMENT 1 COMPARISON OF CONSUMMATORY AND CONDITIONED PECKING RESPONSES}

Conclusions as to the similarity of ingestive and conditioned response form should be based upon direct, quantitative comparisons of the movement patterns involved in the two behaviors. Such a comparison requires the identification of a specific set of response parameters that can be measured for both behaviors in the same subjects. From this standpoint, previous studies of pecking response topography are limited in several respects.

First, in none of the previous studies have the response topographies of ingestive and conditioned pecks been directly compared in the same subjects. Second, many of the studies (e.g., Jenkins \& Moore, 1973; Spetch, Wilkie, \& Skelton, 1981) have relied upon observer's indirect and qualitative ratings of response form. These provide no information as to which topographic features were being discriminated by the judges or as to the consistency with which such criteria were used. Third, even when specific topographic parameters (e.g., force, duration) have been specified, they have been measured only for conditioned keypecks but not for ingestive responses. Finally, none of the previous studies have provided any data on gape, which is an important topographic feature of both ingestive and conditioned pecking responses (Klein, Deich, \& Zeigler, 1985; LaMon \& Zeigler, 1984).

In the present experiment, we have measured four features of the pecking response in order to characterize and compare the topographies of eating and drinking responses and those of conditioned keypecks produced with either food or water reinforcers. An autoshaping procedure was used because the presentation of a signal (lighted key) predicts the delivery of a reinforcer, but reinforcement is not contingent upon the form of the response.

\section{Method}

Subjects

Ten experimentally naive, adult male White Carneaux pigeons were obtained from a commercial breeder and housed in individual cages in an animal room with an ambient temperature of $22^{\circ}-27^{\circ} \mathrm{C}$. Two groups of 5 birds each were selected at random and placed on either food-or water-deprivation schedules. Food-deprived subjects were maintained at $80 \%$ of their free-feeding weights with an adjusted daily ration of approximately $20 \mathrm{~g}$ of milo (2-5-mm diameter) and free access to water in the home cage. Water-deprived subjects were maintained at about $80 \%$ of their free-feeding weights with adjusted rations of $20-40 \mathrm{ml}$ of water, provided after training sessions, and free access to food in the home cage.

\section{Apparatus}

All measures of response form were obtained with an experimental chamber that contained a floor-mounted, 25-mm-square response key and a hopper modified for the presentation of either water or food reinforcers (LaMon \& Zeigler, 1984). The response key was frosted Plexiglas, which transmitted light for conditioning-signal presentations and incorporated a force transducer (Lafayette instruments No. 76613). The output of the force transctucer was monitored by a voltage comparator that provided onset/offset logic pulses when contact force exceeded or passed below a threshold value of $5 \mathrm{~g}$. Peck durations were timed as the interval between onset and offset puises by a Hewlett-Packard Universal Counter (Model 5325B) and digital timer (Model 5050). The force-transcucer voltage signal for each response was also displayed on an oscilloscope (Tektronix, Model 564), which was triggered by key contact and provided a single-sweep duration of $200 \mathrm{msec}$. These analog signals were photographed by a Grass Instruments C-4 Kymograph Camera. A 35mm instrumentation camera and strobe light triggered by key contact provided a size-calibrated, single-frame photograph of the pigeon's head during each response. Whenever a response triggered the reconding equipment, all recording devices were disabled and could not be reactivated for $0.5 \mathrm{sec}$ to allow the cameras to advance.

\section{Data Analysis}

The size-calibrated photonegatives taken at the moment of key contact were displayed on a microfilm reader to provide data on gape (interbeaktip distance) and eye opening (distance between the eyelids). Measurements of maximum contact force and classifications of force-duration characteristics (see results) were made from the kymograph film records. Key contacts occasionally produced a series of peaks in the force record, but only the force and duration of the first interval above threshold was recorded for each response, since maximum force was nearly always produced on the first peak of any waveform.

\section{Procedure}

Following adaptation to the test chamber, eating or drinking responses were elicited in the chamber by manually placing several seeds or water drops upon the response key. In the first phase of the experiment, a minimum of 30 ingestive responses were recorded for each subject. In the second phase, an autoshaping procedure was imposed with a 6-sec signal presentation followed by 4-sec access to the reinforcer with a $1-\mathrm{min}$ variable intertrial interval. For the food group, autoshaping training consisted of $\mathbf{4 0}$ trials per session with food reinforcers; for the water group, there were 20 trials per session with water reinforcers. For both groups, sessions were conducted on alternate days and training continued until at least 100 keypecks were recorded for each subject.

\section{Results}

Comparison of ingestive behaviors and conditioned keypecks from the same subjects showed great similarity for some measures of response form, but substantial differences for others. Figure 1 compares group means for ingestive and conditioned pecking responses for measurements of force, duration, gape, and eye opening. 


\section{Force}

Ingestive pecks involved relatively low forces, and eating and drinking behaviors did not differ statistically from each other with respect to force. However both eating and drinking pecks involved significantly lower forces than did conditioned keypecks [eating vs. food keypecks, matched $t(4)=3.82, p<.02$; drinking vs. water keypecks, matched $t(4)=8.38, p<.002]$. Keypecks with food reinforcers produced the highest average force $(88.5 \mathrm{~g})$, but the difference between the means for foodreinforced and water-reinforced keypecks was not statistically significant.

\section{Duration}

The mean contact durations for eating pecks and keypecks with either food or water reinforcers were all approximately $9 \mathrm{msec}$; however, the mean duration of drinking responses was nearly twice as long. Although statistical comparison of the duration means for eating and drinking pecks yielded a significant difference $[t(8)=5.22$, $p<.001$ ], there were no significant differences among the duration means for eating and keypecks with either food or water reinforcers.

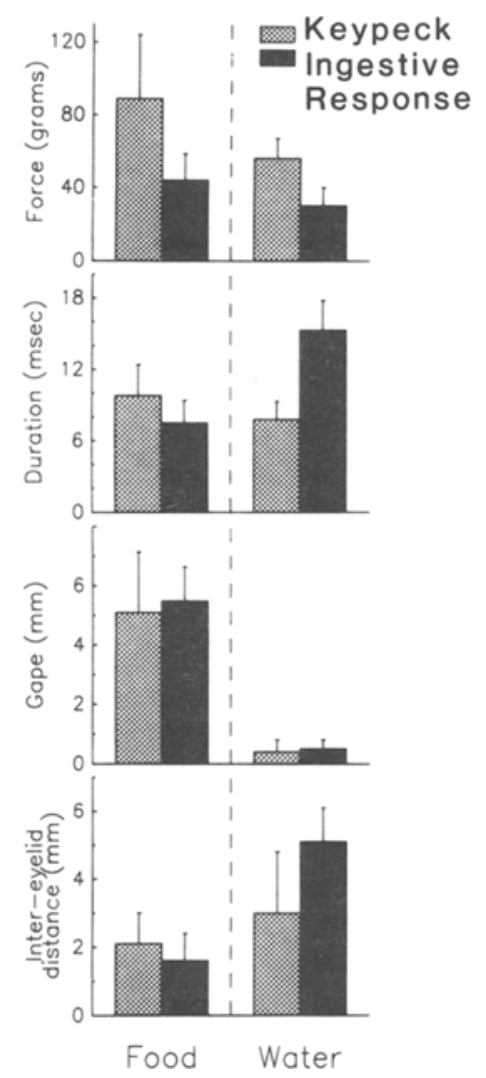

Figure 1. Topographies of drinking, eating, and conditioned keypecks reinforced with food or water. Group means and standard deviations are shown for the force, duration, gape size, and intereyelid distance obtained for each behavior.

\section{Gape}

For both eating and drinking, the mean gape of the ingestive response was nearly identical to the mean gape of its conditioned keypeck counterpart reinforced with either food or water. However, the mean gapes for eating and food-reinforced keypecks (about $5.5 \mathrm{~mm}$ ) were substantially greater than the mean gapes for drinking and keypecks reinforced with water $(0.4 \mathrm{~mm})$.

\section{Intereyelid Distance}

During eating, birds typically had the eyes closed at the moment of substrate contact; during drinking, the eyes closed partially during head descent, but reopened when contact with the water was made. Eating and keypecking with food reinforcers both produced small mean intereyelid values of less than $2.0 \mathrm{~mm}$. Keypecks obtained with water reinforcers showed considerable variation in the amount of eye opening, with a mean intereyelid distance of $3.0 \mathrm{~mm}$. Examination of individual responses indicates that this variability reflects a heterogeneous assortment of open-eye and closed-eye responses, rather than a homogeneous population of responses made with the eyes half closed. Drinking produced the largest mean intereyelid distance of $5.0 \mathrm{~mm}$, indicating that many drinking responses were recorded with the eyes fully open.

\section{Force-Duration Characteristics of Pecking Responses}

Examination of the oscilloscope records of individual pecks suggested that the waveforms might be classified into several types, each of which could be associated with a particular ingestive or conditioned pecking behavior. Figure 2 presents typical oscilloscope records for three classes of pecking response. Eating and food-reinforced pecks typically produced waveforms with a single peak of relatively high force and a rapid onset and termination (Figure 2A). Following such a peck, the bird's head was withdrawn several centimeters above the key prior to initiation of the next peck. Drinking produced waveforms of relatively low force, although force often remained above threshold for a substantial part of the $200-\mathrm{msec}$ record (Figure 2B). For these responses, the bird's beak remained in contact with the key during a series of opening/closing movements as water was ingested. A third distinguishable peck type was associated with conditioned keypecks reinforced with water. This response produced a force record with two components-a single high-force peak of short duration followed by a number of brief lowforce contacts (Figure 2C). Observations revealed that water-reinforced birds often made a rapid peck at the key, after which the head was not withdrawn but remained in the vicinity of the key while the beak made a series of opening/closing movements.

In order to relate waveform characteristics to pecking behavior in a more systematic manner, we divided the waveforms into one of the following classes on the basis of force and duration characteristics: 


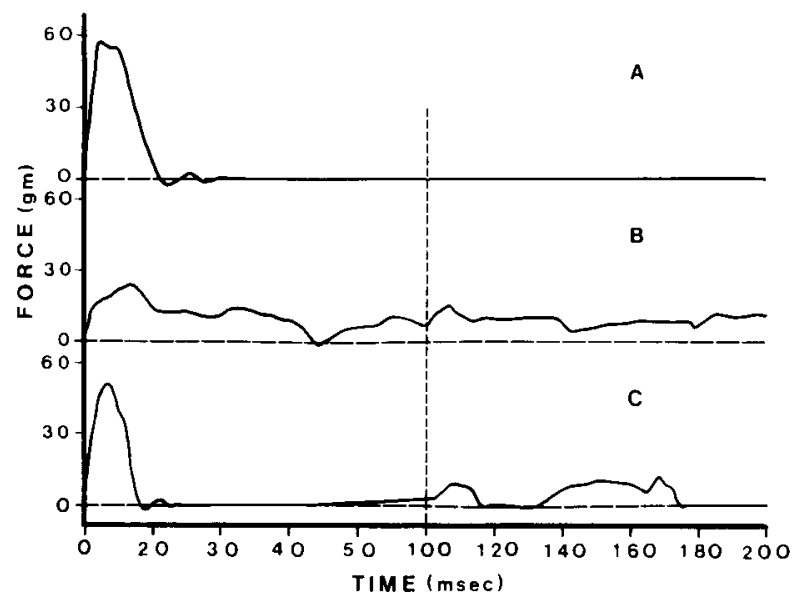

Figure 2. Three representative oscilloscope records illustrating the force-duration waveform characteristics of typical keypeck responses. Waveforms were obtained from photographs of oscilloscope traces of force transducer sigarls. (A) Transient contact, (B) low-force, sustained contact, (C) high-force, sustained contact.

Type 1. Transient-contact responses, in which force exceeded threshold and all key contact was terminated within the first $100 \mathrm{msec}$ of the oscilloscope record.

Type 2. High-force, sustained-contact responses, in which force exceeded $35 \mathrm{~g}$ but key contact was maintained or recurred beyond the first $100 \mathrm{msec}$ of the oscilloscope record.

Type 3. Low-force, sustained-contact responses, in which force was less than $35 \mathrm{~g}$ but key contact was maintained or recurred beyond the first $100 \mathrm{msec}$ of the oscilloscope record.

The force criterion of $35 \mathrm{~g}$ was chosen to differentiate between high-velocity pecks and low-force key contacts. The duration criterion of $100 \mathrm{msec}$ distinguishes sustained pecks, in which the bird's beak remained on or near the key, from any type of apparatus artifact (e.g., key bounce after a high-force impact).

Figure 3 shows the relative frequencies of these three response classes during ingestive and conditioned pecking. Comparison of eating and drinking responses shows that the majority of drinking responses involved sustained contact, whereas the eating responses were predominantly of short duration. By contrast with ingestive pecks, a very high proportion of both food- and water-reinforced keypecks were transient-contact responses. The response records of food-reinforced birds showed almost exclusively single peaks of relatively high force and short duration. In comparison, records of water-reinforced birds showed slightly greater proportions of both types of sustained-contact responses. It should be noted, however, that although keypecks produced with different reinforcers tended to be quite similar in having a majority of highforce transient contacts, they were distinguished unambiguously with respect to gape. The transient-contact keypecks of food-reinforced birds were made with large
(4-6 mm) eating-type gapes. Water-reinforced birds made their transient-contact pecks with very small $(<1 \mathrm{~mm})$ drinking-type gapes.

\section{Discussion}

\section{Methodological Considerations}

The results of any study of response form will always reflect, in part, an interaction between the characteristics of the response and the constraints imposed by the measurement system. Although most previous studies of pecking response topography have employed cinematographic procedures (e.g., Zeigler et al., 1980; Klein et al., 1983), the present photographic data were collected using single-frame still photographs. The former technique produces a continuous record of the behavior; the latter provides a sample of the behavior at a single instant in time-the moment of beak contact with the response key. Similarly, the force/duration measurement system did not record pecks with forces below a criterion threshold, and data for force and duration were obtained only for the first above-threshold key contact of any response. The durations represent the time that force applied to the key remained above threshold; simultaneously, the force record was displayed on an oscilloscope that provided a relatively brief $(200 \mathrm{msec})$ "time window" for examination of peck waveforms.

Our system also differed in its mechanical properties from the key-activated microswitch systems previously

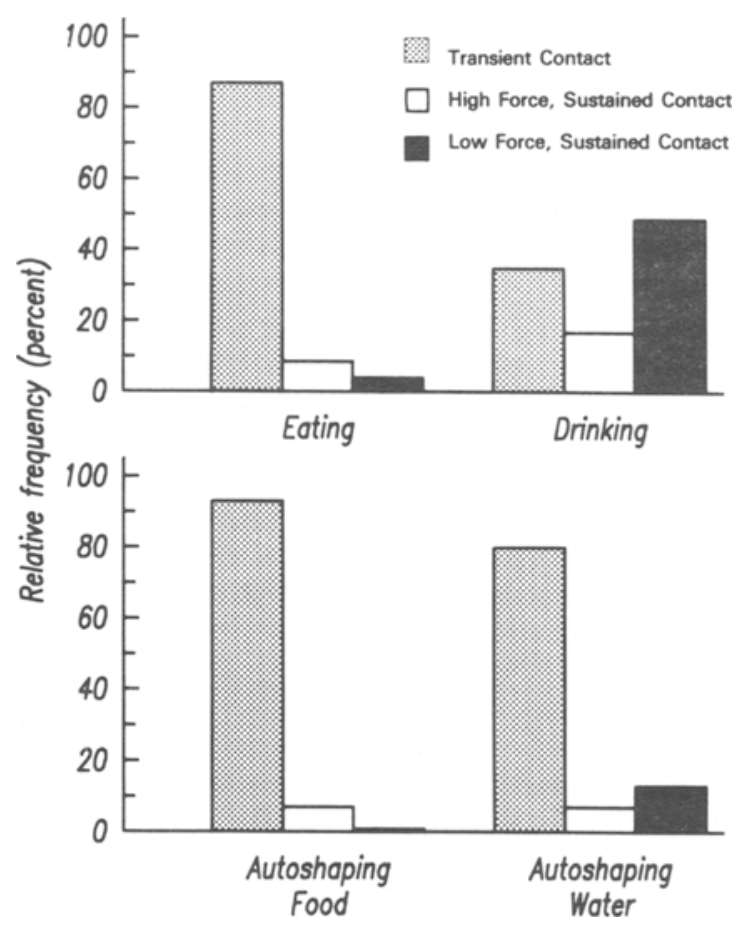

Figure 3. Relative frequencies of the three force-duration response types are shown for ingestive behaviors and conditioned keypecks with either food or water reinforcers. 
used to time peck durations. Because of their mass and the force required to overcome the return-spring of the microswitch, such devices are relatively insensitive to rapid force changes applied to the key, but do provide a measure of the interval between the initial beak contact and the final beak withdrawal. In addition, the wallmounted mechanical configuration and spring tension of the particular microswitch used would undoubtedly affect any timing measurements, so that comparisons of absolute peck durations obtained from different apparatus cannot be made.

\section{Analysis of Topographic Features}

Force. Our results probably overestimate the forces generated during ingestive pecks. On many eating trials, the number of pecks recorded was less than the number of seeds ingested, implying that some of the pecks failed to trigger the recording system even though it was set for a threshold value of $5 \mathrm{~g}$. (Additional observations from our laboratory indicate that eating pecks can produce forces of less than $1 \mathrm{~g}$.) Moreover, prior to contact with the seed, the velocity of head descent slows considerably (Klein, Deich, \& Zeigler, 1985). These observations suggest that the eating peck represents a controlled grasp of the seed. In contrast, the conditioned keypeck seems to involve a strike at the key and generates significantly higher impact forces. These forces were in the range previously reported for conditioned pecks (Jenkins \& Moore, 1973; Spetch et al., 1981) but exhibited considerable variability. Because of that variability, differences in the force of food-versus water-reinforced keypecks did not attain statistical significance.

Because both eating and drinking pecks consistently yielded lower forces than did conditioned keypecks, we examined whether force differences between ingestive and conditioned responses might have been due to the absence of an appropriate three-dimensional target in the conditioning situation (see Wasserman, 1981). A large seed was cemented to the center of the key during a final autoshaping session. In this situation, with an object placed on top of the key/transducer, keypeck force was undiminished. At first, most birds directed pecks at the seed when the signal was illuminated, but these pecks were made with substantial force (initially forces seemed higher as the birds attempted to dislodge the seed). However, within several trials, all birds began to place their pecks on the periphery of the key. This change in peck location suggests that although the propensity to peck may be produced by Pavlovian contingencies (Schwartz \& Gamzu, 1977), control of peck location may show the influence of instrumental contingencies.

Duration. Cinematographic data (Klein et al., 1983; Zeigler et al., 1980) indicate that eating involves a single opening and closing movement of the beak followed by head withdrawal for each seed ingested, whereas drinking involves a series of beak movements with the head lowered. These differences in topography gave rise to sig- nificant differences between the measured durations of eating and drinking responses, and if the recording system had measured the amount of time that the beak was held close to the key, these differences would have been substantially greater. The durations of eating pecks and conditioned keypecks with either food or water reinforcers were similar because subjects in both conditioning situations typically made many high-velocity, transient-contact pecks at the key.

The notable difference between the topography of drinking and that of water-reinforced keypecks reflects the fact that many of the conditioned responses proved to have two distinct components: one or more high-force, transient-contact pecks made with the beak almost closed, followed by a series of rhythmic opening/closing movements of the beak made on or near the key. This initial transient-contact component provided the majority of the durations recorded for water-reinforced keypecks and so yielded force-duration characteristics similar to those of food-reinforced keypecks. The terms rooting and mumbling have been used to describe what we have referred to as the second component of the water-reinforced keypeck, and these movements have been reported to characterize the keypecks made by water-reinforced pigeons (e.g., Woodruff \& Williams, 1976).

In the present study, the incidence and duration of these sustained mumbling responses was probably underestimated. By contrast with the transient-contact pecks, which were usually directed at the lighted response key, mumbling was frequently directed at the floor and would not have been recorded. Moreover, mumbling does not involve discrete pecks, but a series of beak movements that may produce intermittent contact with the substrate. Because the duration timer recorded only the interval for which key contact was above the force threshold, such behavior was not necessarily identified as a long-duration, sustained-contact peck.

Eye opening. For both eating and drinking responses, the eyes close during head descent and do not reopen until movement has ceased (i.e., shortly after contact with the seed or water). Since most transient-contact pecks triggered the camera at the end of a rapid head descent when the eyes had not yet opened, both eating responses and food-reinforced keypecks typically yielded photographs in which the eyes appeared closed. In contrast, drinking responses could trigger the camera at two points; first, after the initial head descent, when the eyes were still closed, and then, during ingestion, when the eyes were often fully open. Thus, the photographic data both for drinking and for water-reinforced keypecks included both eye-closed and eye-open responses. This heterogeneity was particularly evident for water-reinforced keypecks in an increased standard deviation and a mean about midway between the values for eating and drinking responses.

Gape. Previous studies have indicated that drinking responses invariably have small gapes (i.e., $<1.0 \mathrm{~mm}$; Klein et al., 1983) and that the peak gape of eating pecks 
varies with the size of the food object (Deich et al., 1985; LaMon \& Zeigler, 1984). Our data show similar differences for ingestive behaviors, and confirm that conditioned keypecks with water reinforcers also have very small gapes, whereas the gapes of food-reinforced keypecks approximate the size of ingestive gapes made to the reinforcer.

\section{Relationship Between Reinforcer Type and Peck Topography}

Neither eye-opening nor gape has been examined systematically in any previous studies, although differences with respect to both are evident in Jenkins and Moore's (1973, Figure 2) photographs of birds keypecking for food or water. The most frequent basis for judgment mentioned in Jenkins and Moore's (1973) study was that "eatinglike movements were sharp, vigorous pecks at the key, [whereas drinking-like movements] involved slower more sustained contacts" (p. 165). Subsequent reports have focused on force and duration measures and reported consistent differences between keypecks reinforced with food or water (e.g., Schwartz, 1977; Spetch et al., 1981). Such reports of greater durations for water-reinforced keypecks indicate that repetitive beak movements (mumbling) in contact with the key were apparently recorded as longer durations by the transducing systems used in those studies.

In previous studies, the resemblance of keypecks produced with either food or water reinforcers to the pigeon's eating and drinking behaviors has been emphasized and this similarity has been central to theoretical interpretations of the autoshaping situation (i.e., Jenkins \& Moore, 1973; Woodruff \& Williams, 1976). Our findings provide new data demonstrating this similarity, but consistent differences between ingestive and conditioned responses were also obtained. There was extremely close correspondence with respect to the gape of ingestive and conditioned responses with either food or water. Both eating and food-reinforced keypecks involved primarily transient-contact responses, although the eating pecks were made with significantly lower forces. Most drinking responses were classified as sustained contacts with low forces despite the limitations of the transducing system for recording contacts with low forces. However, the high proportion of water-reinforced keypecks classified as transient contacts accurately reflects the fact that these birds were emitting a large number of individual highforce, transient-contact pecks. Water-reinforced birds would frequently emit several such pecks, withdrawing the head between each peck, and then begin to mumble on the key or on the floor between the key and the hopper. The present observations thus qualify previous conclusions regarding the similarity of ingestive and conditioned response topography during autoshaping. They are consistent with the findings of previous studies that have shown that the extent to which conditioned responses resemble their unconditioned precursors depends upon the specific topographic feature being examined (Hilgard, 1936; Martin \& Levey, 1971; Wasserman, 1981; Zener, 1937).

\section{EXPERIMENT 2 THE ORGANIZATION OF RESPONSE FORM}

The generation of behaviors with specific response topographies involves the coordination of discrete response elements into recognizable movement patterns. We may distinguish two theoretical formulations of the control of response form which differ primarily with respect to the role they assign to causal variables in the patterning process.

At one extreme, we may conceive of the patterning of behaviors such as eating, drinking, grooming, and so forth, as being centrally preorganized with respect to form. The form of stereotyped responses depends upon an innate neural organization, and within this conceptual framework, the control of response form is equivalent to the selective activation of one or another fixed behavior pattern. Alternatively, we may view a given response form as being continuously constructed from a number of movement elements mediated by different effector systems. For the pigeon's pecking response, these would include the muscles and skeletal structures of the neck, jaw, and eyelid, which control respectively, head movements, gape, and eye-closure during pecking. In this account, the control of response form involves the integration of multiple variables that modulate the different effector systems to produce changes in response form.

With respect to the form of the pecking response, the first account predicts that regardless of how causal variables are manipulated, response topographies should fall into one or another mutually exclusive response classthat is, eating-type or drinking-type pecks, with no intermediate forms. The second formulation envisages the potential for a continuum of pecking response topographies, from eating pecks, through pecks of intermediate form, to drinking pecks. Experiment 2 represents a preliminary attempt to distinguish between these two theoretical accounts. The experiment was designed to produce a controlled transition between two different forms of the conditioned keypeck in order to examine the way in which such differences are brought about.

\section{Method}

The subjects were 8 of the pigeons used in Experiment 1, 4 each from the food and water groups. Following the completion of the Experiment 1 acquisition sessions, the subjects were placed on a combined food- and water-deprivation schedule. Autoshaping training continued in a series of transition sessions in which both food and water reinforcers were presented with equal probability during each 40-trial conditioning session, with the order of reinforcer presentation varied by random selection for each trial. The birds that acquired keypecking with food reinforcers received three tran- 
sition sessions. Those trained with water reinforcers received six transition sessions, because water-trained birds initially had lower response rates and we wished to examine the effects of extended transition training. All subjects then underwent a third (alternatereinforcer) training condition during which the original food group was water deprived and trained using water reinforcers and the original water group was food deprived and trained using food reinforcers.

\section{Results}

Using the force/duration classifications of peck waveforms described in Experiment 1, we have plotted in Figure 4 the relative frequencies of each type of keypeck as the birds proceeded from an acquisition condition, through the transition condition, to a final alternatereinforcer condition. For the food group (Figure 4, top) more than $90 \%$ of the pecks made during the final acquisition session were of the transient-contact type, and such pecks also account for more than $70 \%$ of the responses made in the last acquisition session by the water group (Figure 4, bottom). However, during the course of the experiment, the two groups showed complementary changes in the relative proportions of each peck type. By the end of the alternate-reinforcer condition, the proportion of transient-contact pecks for the water-to-food group (Figure 4, bottom) had increased to a level similar to that

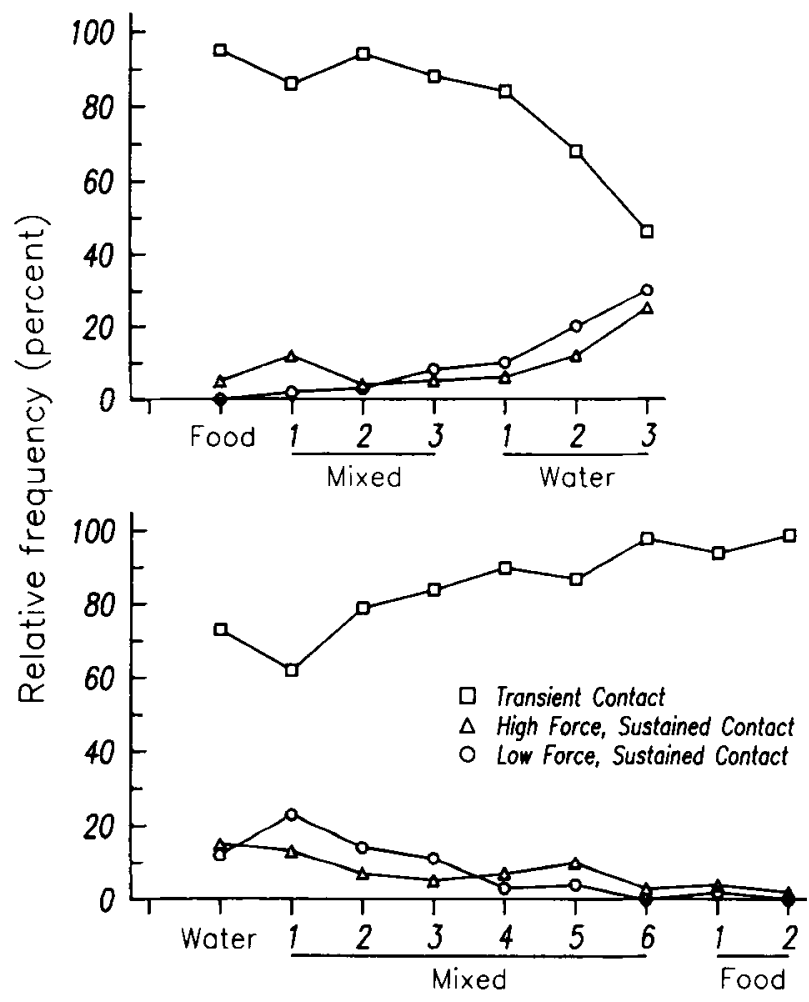

Figure 4. Relative frequencies of the three force-duration response types plotted as a function of successive sessions in Experiment 2. One group begen training with food reinforcers (top); the other group began with water reinforcers (bottom). seen initially in the food-acquisition group (Figure 4, top). Conversely, the proportion of transient-contact responses in the food-to-water group declined substantially throughout the experiment as the proportions of sustained-contact responses increased.

To illustrate the manner in which keypeck form varied, the group means and standard deviations for each component of peck topography were plotted in Figure 5 for the final acquisition session and across successive sessions of Experiment 2. For intereyelid distance, peck force, and duration, the transition condition did not produce a systematic change in the mean values, although duration measures were more variable with water reinforcers. In contrast, gape showed substantial changes across the experimental conditions. As subjects proceeded from water reinforcers, through the transition sessions, to the alternate-reinforcer (food) condition (Figure 5, right), gape increased gradually from a mean of $0.3 \mathrm{~mm}$ to a final value of $4.3 \mathrm{~mm}$. Conversely, the change from food reinforcers, through transition sessions, to the alternatereinforcer (water) condition (Figure 5, left) was accompanied by a corresponding decrease in gape from a mean of $5.7 \mathrm{~mm}$ to a final value of $0.8 \mathrm{~mm}$. The gradual change of mean gape across sessions was also seen in the data for individual subjects (not shown). Thus, although the means for the final acquisition sessions exemplify the typical gape values of food-reinforced and water-reinforced keypecks, by the end of the transition sessions, both groups showed mean gape values $(2.5 \mathrm{vs} .2 .1 \mathrm{~mm})$ that were similar and intermediate between those seen with food or water reinforcers alone.

The substantial changes in mean gape made it possible to examine, for individual subjects, the way in which these changes were produced. The frequency distributions of gape sizes emitted by individual subjects are plotted for successive sessions in Figure 6. Food-reinforced subjects in the final acquisition session produced relatively broad distributions of gape sizes with very low proportions of small gapes (Figure 6a). During the transition sessions, there were gradual reductions in the proportions of gapes at the large end of the distribution accompanied by increases in the proportions of smaller gapes. For 3 of the 4 subjects that acquired keypecking with food reinforcers (Figure 6a; Birds 237, 812, and 282), the first transition session produced an immediate shift to smaller gapes. For 1 bird (237), the shift to smaller gapes was so marked that, by the third transition session, more than $95 \%$ of the gapes emitted were less than $1.0 \mathrm{~mm}$, even though $50 \%$ of the reinforcers received were food. Throughout the alternate-reinforcer condition with $100 \%$ water reinforcement, all of the birds continued to increase the proportions of smaller gapes, although several subjects continued to emit some larger gapes.

In the final acquisition session with water reinforcers (Figure 6b), all subjects produced keypecks with very small gapes, with 3 birds having all responses below 



Figure 5. Group means and standard deviations for individual elements of keypeck topography plotted as a function of the successive sessions in Experiment 2.

$1.0 \mathrm{~mm}$. During the first few transition sessions, each subject continued to emit keypecks with small gapes, but by the fourth session, all subjects began to show gradual increases in the proportions of responses with intermediate and larger gapes. During the alternate-reinforcer sessions, the distributions for all birds broaden and shift to the right, showing continued reductions in the number of very small gapes and substantial increases in the proportions of larger gapes.

A detailed examination of the data for individual birds indicates that these distributions are not composed of individual trials on which subjects emitted either large-gape, food-type keypecks or small-gape, water-type responses. The occurrence of a particular gape size was not systematically related to the type of reinforcer received on the previous trial, and during single trials, different gape sizes were recorded for successive responses. For subjects in the food-reinforced acquisition group, the shift from large to small gapes over the experimental sessions is best characterized as a gradual change involving progressive increases in the proportions of intermediate (1-3 mm) and small $(<1.0 \mathrm{~mm})$ gapes. In the water-reinforced acquisition group, the transition sessions were marked by a progressive increase in the proportions of intermediate 

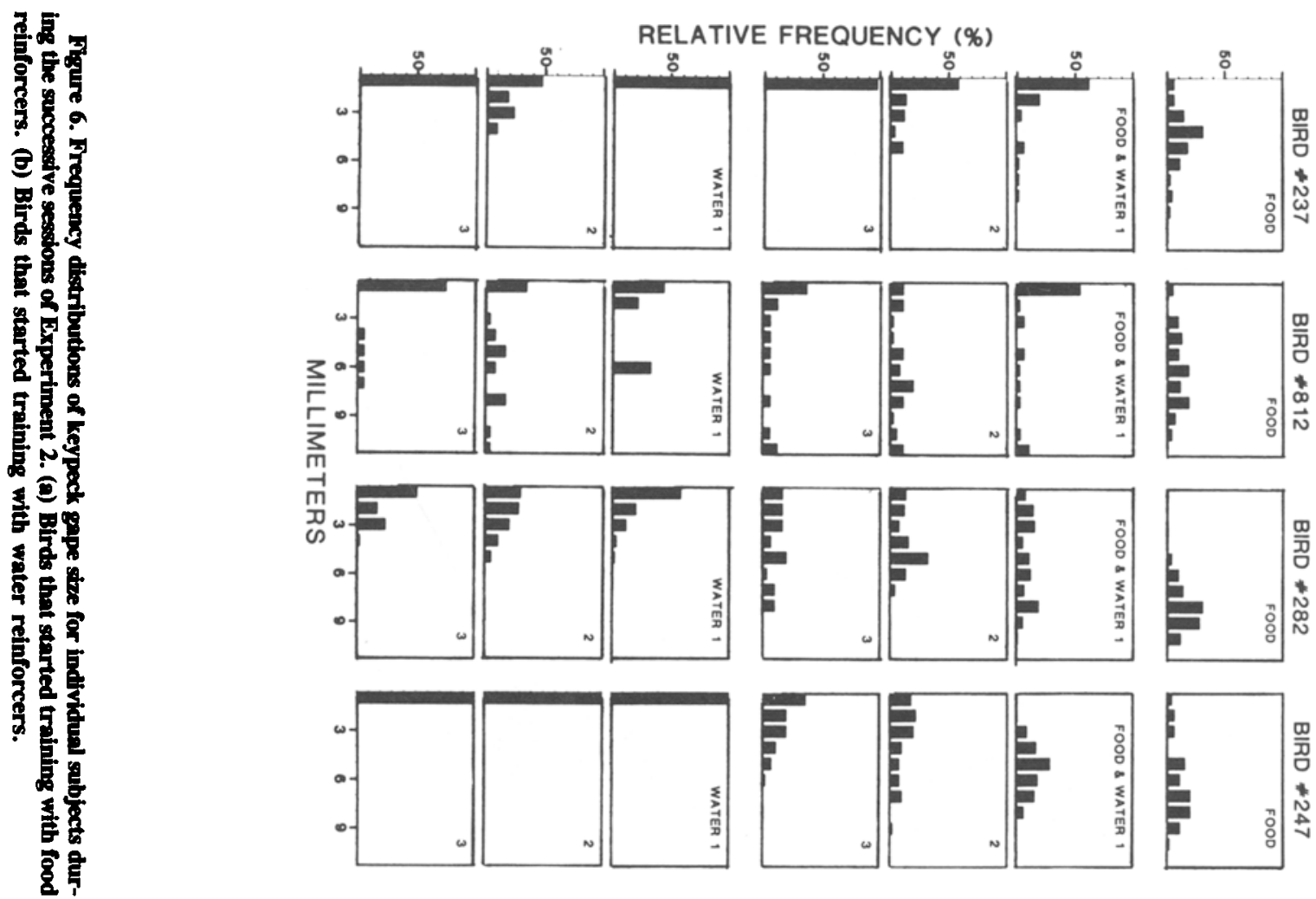

?

RELATIVE FREQUENCY (\%)
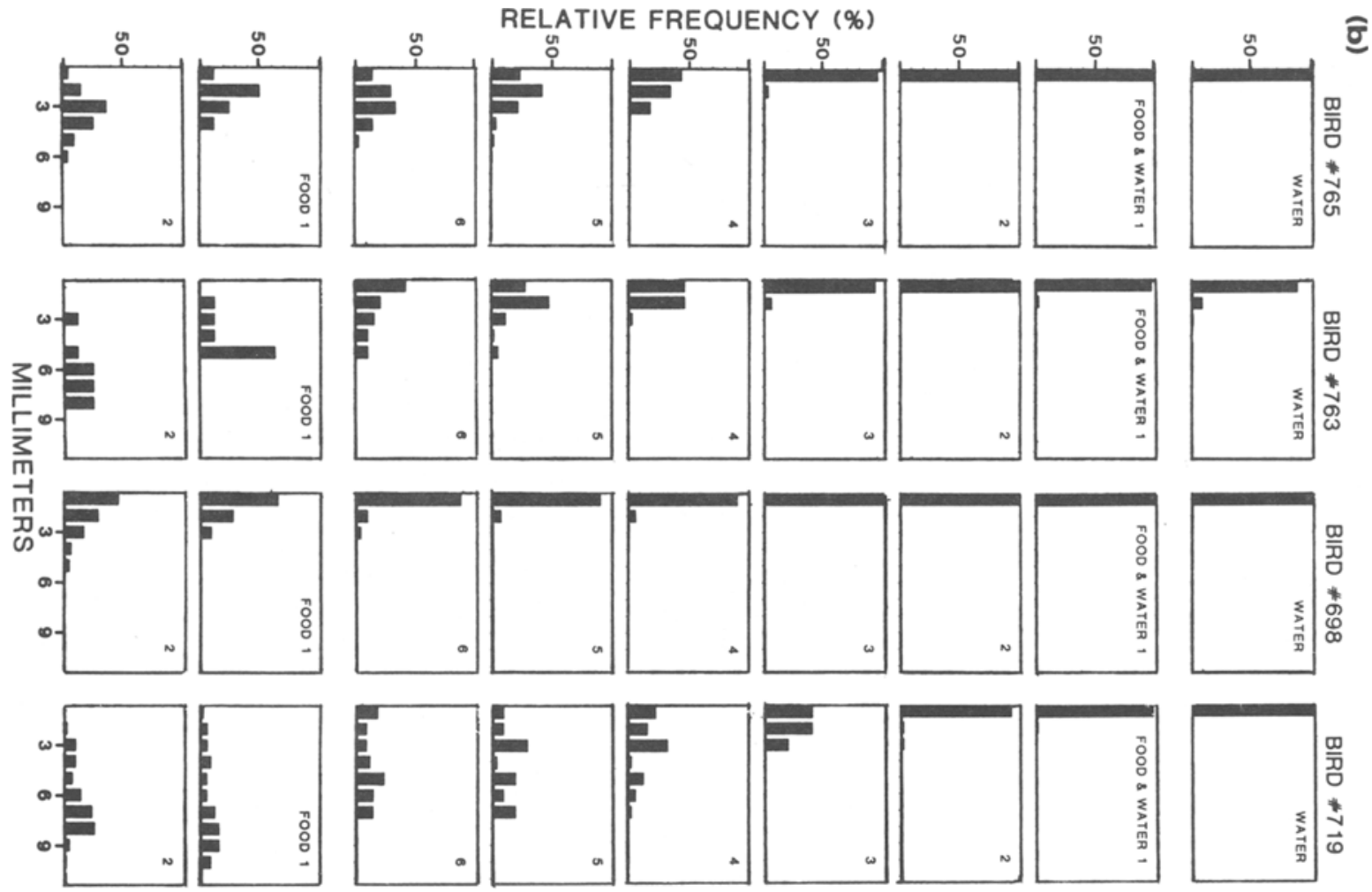
and large gape sizes. Thus, for subjects in both groups, the effects of the experimental conditions upon gape size involved increases in the frequencies of intermediate sizes between 1 and $3 \mathrm{~mm}$. This size range was absent or quite infrequent when either food or water reinforcers were presented alone.

\section{Discussion}

In Experiment 2, changes between two distinctive forms of the pecking responss were produced in order to examine the process by which such changes are made. The results indicate that (1) the experimental conditions produced substantial changes in keypeck topography, and (2) the nature and extent of the changes depends upon the effector system involved.

Although some aspects of response form showed little change, the changes in other measures showed very characteristic patterns. The systematic change in the proportions of responses classified as transient-contact versus sustained-contact (Figure 4) suggests that control of this aspect of keypeck topography is dichotomous in that two distinct types of response were produced. With food reinforcers, the head was withdrawn immediately after each peck, which produced very brief, high-force key contacts. Water reinforcers tended to generate an additional class of low-force, sustained-contact responses (mumbling). Thus, the presence of both food and water reinforcers during the transition condition increased the heterogeneity of response types emitted by birds that had previously received only food reinforcers. For birds that began training with water reinforcers, the frequency of sustained-contact responses decreased during the transition condition. These changes of keypeck topography were therefore produced by varying the relative proportions of two discrete types of response (transient vs. sustained contact) in a dichotomous fashion.

Alternatively, the distributions presented in Figure 6 suggest that the changes in gape size during the transition condition involved a continuous process. There was little evidence of bimodal distributions that would reflect the production of two distinct gape sizes. Instead, the changes involved increases in the frequencies of sizes intermediate between the typical values obtained with food or water reinforcers alone. Moreover, a full range of gape sizes was obtained with both transient-contact and sustained-contact pecks. These findings are not consistent with theories which suggest that a particular form of response results from a unitary organization which determines the values for each of the various response elements. In such a case, we might expect that each of the measures of response form would consistently change together in a dichotomous fashion when a new response type was emitted. However, what we did find was that a change in one response element need not be associated with changes in others, and that each may show a different pattern of change.
Finally, changes in response form were gradual and continued over successive sessions in both the transition and alternate-reinforcer conditions, suggesting that a change in reinforcer conditions takes several sessions to have its full impact. This persistence of the effects of a previous type of reinforcer indicates that the form of a subject's conditioned response represents the cumulative influence of the learned association between the signal stimulus and the reinforcer(s) that was acquired during the preceding conditioning sessions.

\section{GENERAL DISCUSSION}

In many accounts of autoshaping, the conditioned keypeck has been viewed as a species-typical ingestive response whose locus has been shifted during training from the reinforcer to the key. For this reason, attention has been focused almost exclusively on the associative processes by which a signal stimulus acquires the potential for eliciting and directing a specific type of response (e.g., Gamzu \& Williams, 1973; Jenkins \& Moore, 1973; Premock \& Klipec, 1981; Woodruff \& Williams, 1976). This notion of an ingestive behavior that becomes redirected to the conditioning signal was the essence of the "learned-release" hypothesis of Woodruff and Williams (1976). These authors proposed that a "relatively fixed action pattern" for drinking becomes redirected to the response key in the autoshaping situation. In contrast, the "stimulus-substitution" hypothesis discussed by Jenkins and Moore (1973) suggested that the signal comes to serve as a surrogate for the reinforcer. This theory implies that the pigeon is responding to the lighted key as it would to the food or water, and that the topography of the keypeck simply reflects that of the ingestive response.

Several aspects of the present results are difficult to reconcile with either of these accounts, because they indicate that the pigeon is neither responding to the key exactly as it does to food or water nor emitting a movement pattern that is independent of the stimulus properties of the reinforcer and conditioning signal. The finding that keypecks involve significantly higher forces than their ingestive counterparts is not consistent with these accounts, nor is the observation that keypecks reinforced with water exhibit both transient-contact (eating type) and sustainedcontact (drinking type) characteristics. Moreover, the apparent matching of keypeck gape size to the size of seed reinforcers (LaMon \& Zeigler, 1984) is inconsistent with theories that suggest that conditioned response topography reflects only the release of an innately preorganized movement pattern. Because they do not predict either the differences or certain similarities between the form of conditioned and unconditioned responses, neither the stimulus-substitution nor the learned-release formulation provides an adequate account of the control of response form during autoshaping. 
Such an account requires (1) specification of the movement elements constinuting the response, (2) identification of effector systems mediating the movement elements, and (3) elucidation of the role of different variables in the control of each effector system. The putative variables that control keypeck response form are deprivation manipulations, stimulus characteristics of the response key, and associative processes that reflect previous reinforcers. An account of the control of conditioned response form may therefore be organized in terms of the manner in which each of the variables affects each of the effector systems to generate the topography typical of a specific set of training conditions.

For the pigeon's conditioned keypeck, this approach indicates that eyelid movements are probably elicited independently of other pecking-response components by either the visual or vestibular stimulation produced during head descent (Zeigler et al., 1980). Therefore, although eyelid movements are temporally correlated with pecking, they do not reliably distinguish the topography of ingestive or conditioned responses.

Elicitation of the head movements that generate the keypeck is undoubtedly controlled by the conditioning signal through the operation of an associative learning process (Schwartz \& Gamzu, 1977). Visual stimuli from the response key also influence head orientation (peck location) and possibly peck force. The high forces of conditioned keypecks indicate that signal-directed behavior is not simply the redirection of ingestive behavior, but may represent an appetitive/exploratory response to salient stimuli.

Beak movements probably involve different sources of control for their elicitation and patterning. Because the jaw movements that produce gape during food-reinforced keypecking are initiated during head descent, they must be elicited together with head movements by the visual stimulus of the lighted response key. The jaw movements produced during some water-reinforced keypecks are initiated after contact with the substrate. However, the response key cannot be the source of stimuli that control gape size, since gape size may vary systematically in the absence of any corresponding changes in the signal stimulus. Deprivation manipulations are also unlikely to play a direct role in the control of gape size, since both food and water deprivation were in force during the transition condition. The only variable systematically related to gape topography was the type of reinforcer received in previous training. We conclude that the size of keypeck gape is controlled primarily by stimuli present during ingestion of the reinforcer.

Since such ingestive stimuli influence only subsequent responses and are not present during the keypeck, the control of keypeck gape must utilize orosensory information obtained during previous ingestion of the reinforcer. This conclusion is supported by the observation that several sessions with a particular reinforcer were required to produce the full effect upon keypeck gape. Similar ob- servations have been reported by Jenkins and Moore (1973) and Spetch et al. (1981). This indicates that the gape of keypecks is influenced by learned information concerning the properties of the reinforcer, and that the similarity of gapes for conditioned and ingestive responses results from a learned association between the conditioning signal and somatosensory stimuli generated during ingestion of the reinforcer.

\section{Implications for the Study of Response Form}

Detailed analyses of the pigeon's pecking behavior indicate that the generation of a specific response form may involve its construction as an assemblage of elementary movement patterns mediated by separate effector systems with potentially different sources of control (LaMon, 1982; Zeigler et al., 1980; Zweers, 1985). That this principle is applicable to the control of conditioned response form is supported by the findings of the present study. Our observations suggest that, in addressing the problem of conditioned response form, it may not be heuristically useful to think in terms of functionally defined behaviors (e.g., eating pecks, drinking pecks, grooming pecks) with a preorganized and unitary control. Alternatively, we conclude that conditioned keypecks, like their ingestive counterparts, are constructed out of a number of movement elements generated by diverse effector systems. As a result, the interpretation of conditioned response form requires a consideration of the different sorts of control inherent to each effector system.

In addition to its implications for the problem of response form, the present study provides additional information on the control of gape. This element of the pigeon's pecking behavior has a number of features of considerable general interest. The simplicity of the neuromuscular control of beak movements, together with the unambiguous differentiation during eating and drinking, makes gape a useful response system for studies of motor and motivational processes (see, e.g., Deich et al., 1985; LaMon \& Zeigler, 1984; Wild, Arends, \& Zeigler, 1985). For analysis of conditioning processes, it provides a skeletal response that has both directed and undirected aspects, is amenable to both classical and operant conditioning paradigms (LaMon, 1981; LaMon \& Zeigler, 1984; Mallin \& Delius, 1983), and is sensitive to instrumental response differentiation procedures (Deich, Allan, \& Zeigler, 1988). Finally, the adjustment of gape to reinforcer type seen with conditioned keypecks indicates that the pigeon's gape response may provide a useful behavioral system for examining the role of learning processes in sensorimotor control.

\section{REFERENCES}

Deich, J. D., Allan, R. W., Zeigler, H. P. (1988). Conjunctive differentiation of gape during food-reinforced keypecking in the pigeon. Animal Learning \& Behavior, 16, 268-276. 
Deich, J. D., KLein, B. G., Zeigler, H. P. (1985). Grasping in the pigeon: Mechanisms of motor control. Brain Research, 337, 362-367.

Gamzu, E., \& Williams, D. R. (1973). Associative factors underlying the pigeon's keypecking in autoshaping procedures. Journal of the Experimental Analysis of Behavior, 19, 225-232.

Hilgard, E. R. (1936). The nature of the conditioned response: I. The case for and against stimulus substitution. Psychological Review, $\mathbf{4 3}$, 366-385.

Jenkins, H., \& Moore, B. R. (1973). The form of the autoshaped response with food or water reinforcer. Journal of the Experimental Analysis of Behavior, 20, 163-181.

Klein, B. G., Deich, J. D., Zeigler, H. P. (1985). Grasping in the pigeon (Columba livia): Final common path mechanisms. Behavioral Brain Research, 18, 201-213.

Klein, B. G., LAMon, B., \& Zeigler, H. P. (1983). Drinking in the pigeon: Response topography and spatiotemporal organization. Joumal of Comparative Psychology, 97, 178-181.

LAMON, B. (1982). The control of response form: Feeding and conditioned responding in the pigeon (Doctoral dissertation, City University of New York, 1981). Dissertation Abstracts International, 42(11), 4614.

LAMon, B., ZeIGLer, H. P. (1984). Grasping in the pigeon: Stimulus control during conditioned and consumatory responses. Animal Learning \& Behavior, 12, 223-231.

Mallin, H. D., \& Deuus, J. D. (1983). Inter- and intraocular transfer of color discriminations with mandibulation as an operant in the fixed-head pigeon. Behavior Analysis Letters, 3, 297-309.

MARTIN, I., LeVEY, A. B. (1971). The genesis of the classical conditioned response. Oxford: Oxford University Press.

Premock, M., KLIPEC, W. D. (1981). The effects of modifying consumatory behavior on the topography of the autoshaped pecking response in pigeons. Joumal of the Experimental Analysis of Behavior, 36, $277-284$.

SCHWARTZ, B. (1977). Studies of operant and reflexive key pecks in the pigeon. Journal of the Experimental Analysis of Behavior, 27, 301-313.
SChwartz, B., \& Gamzu, E. (1977). Pavlovian control of operant behavior. In W. K. Honig \& J. E. R. Staddon (Eds.), Handbook of operant behavior (pp. 53-97). Englewood Cliffs, NJ: Prentice-Hall.

SPETCH, J., WILKIE, D., \& SkELTON, R. (1981). Control of the pigeon's keypecking topography by a schedule of alternating food and water reward. Animal Learning \& Behavior, 9, 223-229.

W AsSerman, E. A. (1981). Response evocation in autoshaping: Contributions of cognitive and comparative-evolutionary analyses to an understanding of directed action. In C. Locurto, H. Terrace, \& J. Gibbon (Eds.), Autoshaping and conditioning theory (pp. 21-54). New York: Academic Press.

Wild, J. M., Arends, J. A., \& Zeigler, H. P. (1985). Telencephalic connections of the trigeminal system in the pigeon (Columba livia): A trigeminal sensorimotor circuit. Joumal of Comparative Neurology, 192, 175-201.

Wous, B. R. (1968). Difference in manner of pecking a key between pigeons reinforced with food and with water. In A. C. Catania (Ed.), Contemporary Research in Operant Behavior (p. 286). Glenview, IL: Scott-Foresman.

WoOdRUFF, G., WILLIAMs, D. R. (1976). The associative relation underlying autoshaping in the pigeon. Joumal of the Experimental Analysis of Behavior, 26, 1-13.

Zeigler, H. P., Levitt, P., \& Levine, R. R. (1980). Eating in the pigeon (Columba livia): Movement patterns, stereotypy and stimulus control. Journal of Comparative \& Physiological Psychology, 94, 783-794

ZENER, K. (1937). The significance of behavior accompanying conditioned salivary secretion for theories of the conditioned response. American Journal of Psychology, 50, 384-403.

ZWEERS, G. A. (1985). Generalism and specialism in the avian mouth and pharynx. Fortschritte der Zoologie, 30, 189-201.

(Manuscript received May 14, 1987; revision accepted for publication March 9, 1988.) 